\title{
Editorial
}

\section{Accreditation of medical testing laboratories in Sri Lanka, the definite way forward!}

Economic recession or boom, neither will leave Sri Lanka untouched in some way and then, can we isolate our laboratories with satisfaction that we have achieved recommended standards at every level in diagnostic testing per se? The question may leave you pondering. Achieving and maintaining the required standard in medical laboratory testing is a requirement for obtaining international recognition in diagnostic testing. So how is this going to be achieved? Clearly, by the process of accreditation only.

The world accreditation day was commemorated on the 9 th of June 2012 in Sri Lanka as in the rest of the world. This brings us to the realization that the accreditation is upon us as much as global warming, whether we are ready for it or not. So are we ready for this process? Will accreditation take laboratory testing to higher standards and thereby give improved patient care? Is the road to accreditation going to be free of hurdles or a hurdle by itself? Have we at least embarked on the road? These are questions wanting answers. At least the time is on us to seek out the answers.

The entire process of accreditation of laboratories of various sectors, including pathology services has been brought about and to the forefront by the Sri Lanka accreditation board for conformity assessment, which established in 2005, has been the main player in introducing the international standard applicable to Sri Lanka, the ISO $15189: 2007$, with particular relevance to medical laboratories. The stage of laying the knowledge base on accreditation to relevant stake holders has been successfully completed. The next step of building the necessary pool of technical specialty also has been achieved and this pool continues to expand. The difficult task of convincing the users of the pathology laboratory services, the importance of making patient management decisions based on a reliable test report is far from achieved. However there is gradual but slow progress in this direction. Building of the quality infrastructure facilities will have to be worked out much more steadily as these facilities will have to provide long term services to the conformity assessment systems.

The diagnostic laboratories functioning under private enterprises have taken heed to the need for accreditation. The first step of the daunting task to accredit the laboratories within the health ministry is underway by the initiation of a pilot project to develop necessary guidelines. It is also necessary to incorporate the university laboratories providing diagnostic services.

Accreditation process will ensure quality of the test results and that will be, assured quality. Most of the pathology laboratories function at levels of certain standards. The standard is voluntary and not mandatory. With accreditation, compliance to these standards becomes mandatory. Accreditation will not provide mere certification but credibility to the competency claimed by laboratories. Accreditation will build trust with the consumer in all of the sectors. Finally, accreditation will raise the medical testing to internationally 
acceptable and comparable levels. This will place the pathology services in Sri Lanka in an entirely global perspective. So why not we move forward with accreditation of the medical testing laboratories for the benefit of the users of the service and the country as a whole?

Reference

1. SLAB news bulletin 2012 (4); 1: 1-7.

Dr CSP Sosai

Professor Neelakanthi Ratnatunga 